\title{
Cost Minimisation Study of the Impact of Generic Drugs on Glaucoma Management: 1-year Indian Experience
}

\author{
Devindra Sood, ${ }^{1}$ Alka Pandey, ${ }^{2}$ Rajeev Sood, ${ }^{3}$ Nagesh Gupta,,${ }^{4}$ Rohit Sardana,,${ }^{4}$ Ravinder \\ Kumar Bajaj, ${ }^{5}$ Narendra Nath Sood ${ }^{1}$ \\ ${ }^{1}$ Glaucoma Imaging Centre, New Delhi, ${ }^{2}$ Eye 7, New Delhi, ${ }^{3}$ Sood Eye and Maternity \\ Hospital, Kaithal, ${ }^{4}$ Mahabir Dal Hospital, Karnal, and ${ }^{5}$ Bajaj Eye Centre, Panipat, India
}

\begin{abstract}
Aim: To study the medication costs of various topical glaucoma medications using data collected from real world use by patients.

Methods: Patients with primary open angle glaucoma treated at glaucoma clinics in 5 hospitals (1 rural and 4 urban) in northern India from 1 January to 30 June 2008 were enrolled. The number of days each bottle of medication lasted was recorded, and the mean cost per day was computed from the maximum retail price and mean number of days each medication lasted.

Results: 790 of 801 eligible patients completed the study. The mean number of days that a bottle of medication lasted was found to be highest for Xalatan ${ }^{\circledast}$ and Xalacom ${ }^{\circledR}$ at 35.23 days and 35.00 days, respectively. The brand name prostaglandin analogues all lasted for a mean of more than 30 days: Xalatan, 35.23 days (SD, 4.14 days); Lumigan $^{\circledR}, 31.37$ days (SD, 5.31 days); and Travatan ${ }^{\circledR}, 34.84$ days $(S D, 6.51$ days), while the generic eye drops lasted for about 21 days: latanoprost, 20.69 days (SD, 3.69 days) and bimatoprost, 21.39 days (SD, 4.34 days). The cost of the generic medication was less than the brand name medication in all groups (for example, bimatoprost, Indian rupees 9.76 versus Indian rupees 12.33) except for brimonidine/timolol (Indian rupees 8.73 versus Indian rupees 8.66). Further analysis in 2009 showed that, for latanoprost, brimonidine and brimonidine/timolol, the difference between the brand name and generic medications decreased in 2009 over 2008 (in the latanoprost group, the cost difference over the year reduced from Indian rupees 592 in 2008 to Indian rupees 523 in 2009); the cost difference for bimatoprost increased from 2008 to 2009.

Conclusion: When both cost and number of days a bottle lasts were considered over the long term, use of generic medications might not minimise the cost of glaucoma medical management by much when compared with the brand name medication.
\end{abstract}

Key words: Costs and cost analysis, Drugs generic, Glaucoma, open angle, Prostaglandins

Asian J Ophthalmol. 2011;12:192-6.

\section{Introduction}

Glaucoma causes a significant financial burden through the direct costs of medication or other treatment costs and physician consultation costs as well as intangible costs accrued by its impact on quality of life. ${ }^{1} \mathrm{~A}$ European study by Traverso et al showed that the cost of medical management for glaucoma ranged from $42 \%$ to $56 \%$ of the total direct costs for all stages of disease when compliance is assumed to be full. ${ }^{2}$ With the development of the newer glaucoma medications, the direct cost of medical treatment

Correspondence: Dr Devindra Sood, Glaucoma Imaging Centre, P-13 South Extension Part II, New Delhi 110049, India.

Tel: (91 98) 6850 1195;

E-mail: glaucomacentre@yahoo.com has increased, although the indirect costs have decreased due to better control of the disease process and the reduced need for surgery.

In India, where there is minimal insurance or government health cover, almost all medication costs of a treatment are paid for directly by the patients. Therefore, the price of medication considerably influences physicians' prescribing preferences. ${ }^{3}$ Several researchers have performed cost analysis studies between various glaucoma medications..$^{4-6}$ However, these studies have mostly been performed in developed countries, and are of limited use to physicians in India owing to the variations in medication prices and the different healthcare models followed in these countries. Moreover, the methods of analysing the cost of the 
drug have been different, and a detailed literature search did not reveal any studies that assessed the cost by taking into account the number of days for which a bottle lasts, thus giving the true estimate of cost per drop.

This observational study was performed to update the cost minimisation information for glaucoma medications from prior studies and to help physicians in their choice of a cost-effective treatment. The study analysed the medication costs of the various topical glaucoma medications using the data collected from real world use by patients. The study investigated the retail costs of all the topical glaucoma medications used by the patients and evaluated the annual costs of topical medications in a comparison between the original molecules (brand name drugs) and the generic medication.

\section{Methods}

Patients with a prior diagnosis of primary open angle glaucoma and seeking a second opinion at the glaucoma clinics in 5 hospitals (1 rural and 4 urban) in northern India from 1 January to 30 June 2008 were enrolled in the study. The study was approved by a central ethics committee, and all patients provided verbal informed consent.

A questionnaire was verbally administered by a trained social worker in each patient's preferred language (English, Hindi, Punjabi, or Haryanvi). The diagnosis of glaucoma and its severity was confirmed by a single senior glaucoma specialist who visited all the sites and verified the medications used by the patients. The data collected included demographic details, medications used (brand name and generic drugs were differentiated), and duration of topical glaucoma treatment after the initial diagnosis of glaucoma. The number of days that each bottle of medication lasted was also recorded for all patients.

The maximum retail prices (MRP) from the label of each medication at the beginning and the end of study were collected. The mean duration (in number of days) that each bottle lasted was computed. The mean cost per day of each medication was then measured by dividing the MRP with the mean duration in days for eye drops used by more than 30 patients.

The cost differences between the brand name and generic drugs in the same category were further analysed using paired $t$ test
(SAS version 9.1.3; SAS Institute Inc, Cary, USA). Probability values with a significance level of $\alpha=5 \%$ were computed between the brand name and generic drugs within a category used in the study.

The daily cost data were used to calculate the annual cost by multiplying by 365 . In 2009, it was found that the MRP for the various glaucoma medications had changed. Hence, the annual costs at the end of 2008 and 2009 were calculated separately for eye drops used by more than 30 patients.

\section{Results}

790 of 801 eligible patients completed the questionnaire; 11 patients declined to participate. The baseline characteristics of the patients who completed the questionnaire are shown in Table 1. The mean age of the patients was 59.03 years. The mean duration of glaucoma medication use was similar in patients attending glaucoma clinics both in rural (5.14 years) and urban (5.72 years) settings separately and when combined (5.51 years) [Table 1].

The medications used by the patients were as follows:

- $\beta$-adrenergic antagonists or $\beta$-blockers - timolol $0.5 \%$, betaxolol $0.5 \%$, and levobunolol (0.5\%)

- carbonic anhydrase inhibitors - dorzolamide $2 \%$

- cholinergic agents - pilocarpine $2 \%$

- $\alpha$-adrenergic agonists - brimonidine $0.2 \%$

- prostaglandin analogues - latanoprost $0.005 \%$ and travoprost $0.004 \%$

- prostamides - bimatoprost $0.03 \%$

- combination of timolol and dorzolamide

- combination of latanoprost and timolol

- combination of pilocarpine and timolol

- combination of brimonidine and timolol

- combination of bimataprost and timolol.

The average number of days that a bottle lasted was highest for Xalatan ${ }^{\circledast}$ and Xalacom $^{\circledast}$ eye drops at 35.23 days and 35.00 days, respectively. Among the single medications, Xalatan was the most expensive at Indian rupees (INR) 17.18 per day, while betaxolol was the cheapest at INR 1.35 per day. Combigan ${ }^{\circledR}$ was the cheapest combination used by more than 30 patients at INR 8.66 per day (Table 2).

Table 1. Patients' characteristics $(n=790)$.

\begin{tabular}{|lcrr|}
\hline & Rural & Urban & Combined \\
\hline Sex [number (\%)] & & & \\
Male & $159(20.38)$ & $269(34.49)$ & $428(54.87)$ \\
Female & $116(14.87)$ & $236(30.26)$ & $352(45.12)$ \\
Mean age (SD) [years] & $58.72(10.22)$ & $59.19(11.34)$ & $59.03(10.96)$ \\
Mean duration of glaucoma medication use (SD) [years] & $5.14(1.84)$ & $5.72(2.39)$ & $5.51(2.23)$ \\
\hline
\end{tabular}

*Data pertaining to sex was missing for 10 patients. 
Table 2. Economic data of the glaucoma medications used in the study.

\begin{tabular}{|c|c|c|c|c|c|c|c|}
\hline & $\begin{array}{c}\text { Bottle size } \\
\quad(\mathrm{mL})\end{array}$ & $\begin{array}{l}\text { Number of } \\
\text { patients }\end{array}$ & $\begin{array}{c}\text { Number of } \\
\text { days/bottle } \\
\text { Mean (SD) }\end{array}$ & MRP (INR) & $\begin{array}{l}\text { Cost/day (INR) } \\
\text { Mean (SD) }\end{array}$ & $\begin{array}{l}t \text { Value } \\
\text { (df) }\end{array}$ & p Value \\
\hline \multicolumn{8}{|l|}{ Bimatoprost } \\
\hline Lumigan & 3 & 84 & $31.37(5.31)$ & 375 & $12.33(2.34)$ & \multirow[t]{2}{*}{$8.05(213)$} & \multirow[t]{2}{*}{$<0.0001$} \\
\hline Generic: Bimat & 3 & 131 & $21.39(4.34)$ & 200 & $9.76(2.22)$ & & \\
\hline \multicolumn{8}{|l|}{ Latanoprost } \\
\hline Xalatan & 2.5 & 154 & $35.23(4.14)$ & $593.82^{\dagger}$ & $17.18(3.05)$ & \multirow[t]{2}{*}{$3.43(408)$} & \multirow[t]{2}{*}{$<0.0001$} \\
\hline Generic: 9PM, Latoprost & 2.5 & 256 & $20.69(3.69)$ & $318.75^{\ddagger}$ & $16.03(3.56)$ & & \\
\hline \multicolumn{8}{|l|}{$\alpha_{2}$-Agonist } \\
\hline \multicolumn{8}{|l|}{ Brimonidine } \\
\hline \multicolumn{8}{|l|}{$\beta$-Blocker } \\
\hline Timolet, Betagan- $0.5 \%$ (non-selective) & 5 & 258 & $24.20(4.94)$ & $59.30^{\natural}$ & $3.18(0.71)$ & & \\
\hline Generic: Betaxolol (selective) & 5 & 94 & $23.01(4.47)$ & 30 & $1.35(0.25)$ & & \\
\hline \multicolumn{8}{|l|}{ Combination } \\
\hline Combigan & 5 & 56 & $24.38(3.95)$ & 205 & $8.66(1.64)$ & \multirow[t]{3}{*}{$-0.20(146)$} & \multirow[t]{3}{*}{$>0.8394$} \\
\hline $\begin{array}{l}\text { Generic: Brimocom (brimonidine/timolol); } \\
\text { Brimolol (brimonidine/timolol); }\end{array}$ & 5 & 92 & $20.17(4.38)$ & $167.50^{\text {tt }}$ & $8.73(2.06)$ & & \\
\hline Dorzox-T, Dortas-T (dorzolamide/timolol) & 3,5 & 76 & $21.97(5.68)$ & $230.30^{\ddagger \ddagger}$ & $11.13(2.79)$ & & \\
\hline
\end{tabular}

${ }^{*} \mathrm{MRP} /$ bottle $=\operatorname{INR}^{\S} 622.00$; sold as 3 bottles for the price of 2 (MRP/bottle $=$ INR 414.66).

${ }^{+} \mathrm{MRP} / \mathrm{bottle}=$ INR 1187.65; sold as 2 bottles for the price of 1 (MRP/bottle $=$ INR 593.82).

${ }^{\ddagger} \mathrm{MRP} /$ bottle for 9 PM = INR 343.00 and for Latoprost = INR 294.50; the average MRP/bottle = INR 318.75.

$\$$ MRP/bottle for Brimodin = INR 107.25 and for Brimocin = INR 130.00; the average MRP/bottle = INR 118.62.

"MRP/bottle for Dortas = INR 209 and for Dorzox = INR 208; the average MRP/bottle = INR 208.95.

"MRP/bottle for Timolet $=$ INR 47.00 and for Betagan $=$ INR 71.55; the average MRP/bottle = INR 59.30.

${ }^{\star \star} \mathrm{MRP} /$ bottle = INR 1348.00; sold as 2 bottles for the price of 1 (MRP/bottle = INR 674.00).

${ }^{+} \mathrm{MRP} /$ bottle for Brimolol = INR 170.00 and for Brimocom = INR 165.00; the average MRP/bottle = INR 167.50.

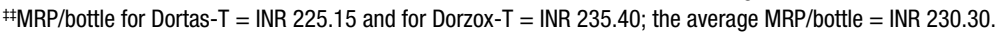

${ }^{\S}$ At the time of publication, US\$1.00 = INR 44.3950 (www.xe.com/ucc/).

Abbreviations: $\mathrm{CAl}=$ carbonic anhydrase inhibitors; INR = Indian rupees; MRP = maximum retail price.

Among the prostaglandin analogues, all the brand name drugs lasted for a mean of more than 30 days: Xalatan, 35.23 days (SD, 4.14 days), Lumigan ${ }^{\circledR}, 31.37$ days (SD, 5.31 days), and $\operatorname{Travatan}^{\circledR}$, 34.84 days (SD, 6.51 days), while the generic eye drops lasted for a mean of approximately 21 days: latanoprost, 20.69 days (SD, 3.69 days) and bimatoprost 21.39 days (SD, 4.34 days) [Table 2].

The cost per day of the generic drugs was lower than that of the brand name drugs except for Combigan, which was cheaper than the generic version (brimonidine and timolol, $p>0.8394$ ) [Table 2]

The 2-year cost analysis showed that, for latanoprost, the difference between the brand name and the generic drugs was INR 592.00 in 2008, which reduced to INR 523.00 in 2009. For brimonidine, the difference decreased from INR 810.11 in 2008 to INR 512.97 in 2009. For bimatoprost, the difference increased from INR 955.22 in 2008 to INR 982.58 in 2009. The differences in the annual costs of the brand name and generic drugs using the 2008 and 2009 MRP are shown in Figure 1.

\section{Discussion}

In a country such as India where health care tends to be paid for by patients, physicians usually take decisions based on the cost of a drug when a choice needs to be made between a brand name or a generic drug, assuming that all other factors are equal. In the case of glaucoma medications, other factors include the number of days a bottle lasts and the efficacy and/or tolerability of the generic drug.

This study identified that each bottle of brand name drug lasted longer than the generic drugs. Although the cost per day comparisons of the generic versus the brand name medications indicated that generic medications were cheaper than the brand name medications (with the exception of Combigan), the difference was not as much as that perceived when only the cost of the bottle was taken into consideration. Additionally, by the end of the study, it was found that the MRP for the various medications had changed, so the annual costs at the end of 2008 and 2009 were calculated separately from the MRP. Analysis of the difference in 
Figure 1. Cost difference between brand name and generic drugs for 2008 and 2009.

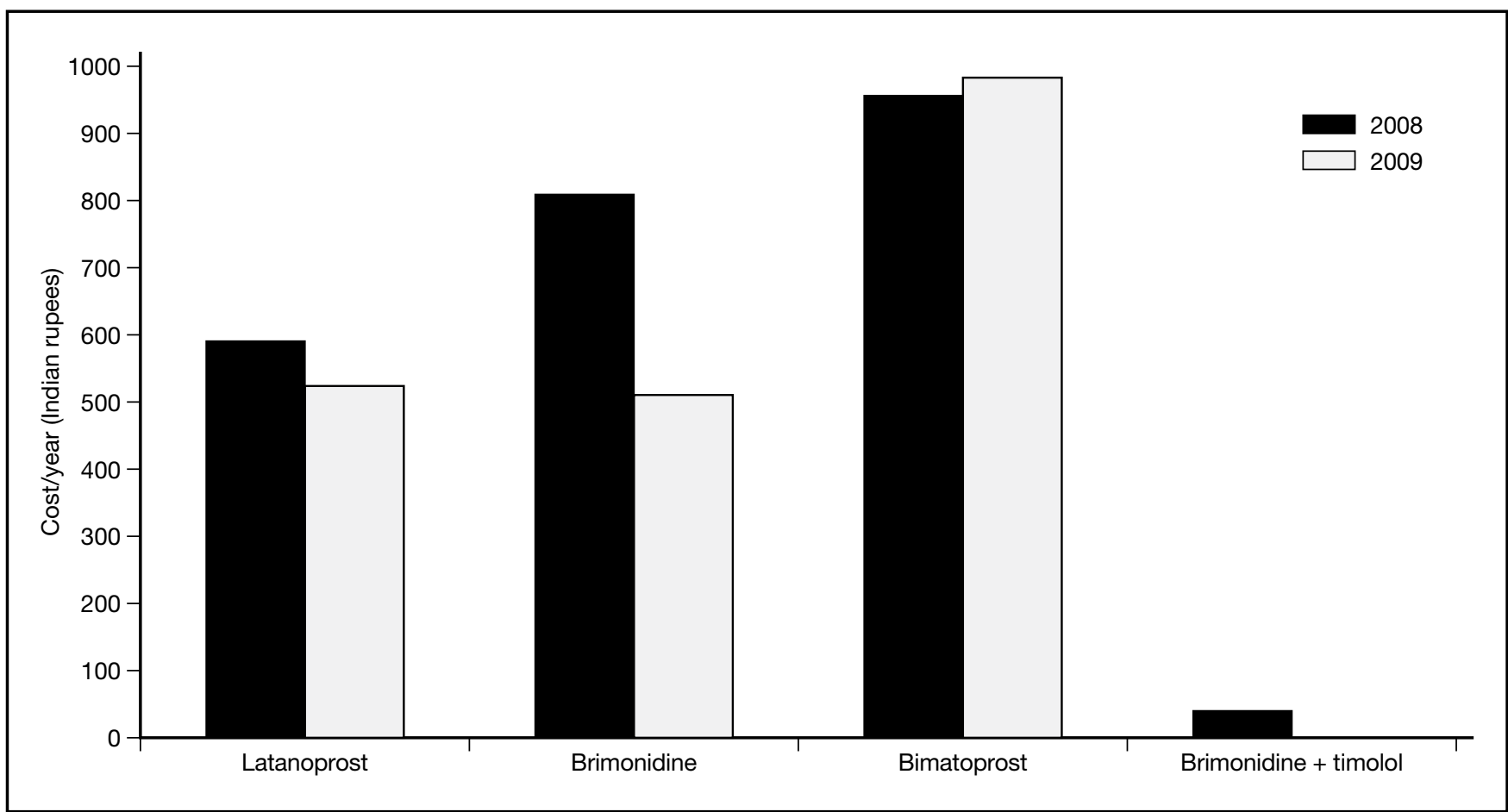

costs between 2008 and 2009 demonstrated that the annual cost difference reduced during 2009, either due to the increased cost of the generic drugs or the reduced cost of the brand name drugs.

The different reasons for a brand name drug to last longer than the generic drugs could be waste of medication due to large drop size or poor bottle design or quality. A literature search did not show any study specifically done on these factors. However, reliability of drop size and dose variability has been known to be a concern for glaucoma treatment. ${ }^{7}$ If the drop volume is large, the number of drops from the same amount of drug would be reduced. Waste or accidental administration of more than the prescribed dose occurs in a significant portion of patients with glaucoma. Therefore, a bestcase scenario with none of the drops being wasted is considerably different to that of real-world use. ${ }^{1}$ Hence, this study compared the costs of various brand name and generic medications based on patients' actual use. However, with patients' average medication use being $>5$ years in this study, the effect of waste incurred by initial users would be reduced. This study did not examine the efficacy or tolerability factors of the various glaucoma medications used by the patients.

This cost minimisation analysis was done on the basis of the brand name and generic drugs having equivalent efficacy and tolerability profiles. However, a small cross-over study has compared the efficacy and safety of Xalatan with a generic drug. ${ }^{8}$ Narayanaswamy et al noted that Xalatan reduced IOP more than the generic drug. ${ }^{8}$ The incidence of conjunctival hyperaemia and ocular irritation was also lower in patients using Xalatan compared with latanoprost. According to the authors, chemical equivalence may not necessarily be translated into therapeutic equivalence. ${ }^{8}$ Although larger studies are required to substantiate this result, similar concerns have been shared by other authors, and studies have demonstrated equivalence of the generic drug with branded prednisolone, diclofenac sodium ophthalmic solution, ciprofloxacin ophthalmic eye drops, and ketorolac. ${ }^{9-13}$

A few global studies have also noted an increase in the price of topical medications for glaucoma over the years, which contributes to the overall rise in direct costs of glaucoma medical management. ${ }^{1-6}$ The results of this study aid physicians in making drug choices to help reduce the economic burden of glaucoma.

In summary, considering the real costs per day, generic drug prescription may not minimise costs over time. Since this study was done in only 1 country, the results cannot be generalised. However, the introduction of newer medications and swift price changes warrants continuous study across various geographical regions to update the cost-analysis information for glaucoma medical management throughout the world.

\section{References}

1. Rylander NR, Vold SD. Cost analysis of glaucoma medications. Am J Ophthalmol. 2008;145:106-13.

2. Traverso CE, Walt JG, Kelly SP, et al. Direct costs of glaucoma and severity of the disease: a multinational long-term study of resource utilization in Europe. Br J Ophthalmol. 2005;89:1245-9.

3. Parikh RS, Parikh SR, Navin S, Arun E, Thomas R. Practical 


\section{Impact of Generic Drugs on Glaucoma Management}

approach to medical management of glaucoma. Indian J Ophthalmol. 2008;56:223-30.

4. Azuara-Blanco A, Burr J. The rising cost of glaucoma drugs. $\mathrm{Br} \mathrm{J}$ Ophthalmol. 2006;90:130-1.

5. Knox A, Barry M, McGowan B, O'Brien C. The rising cost of glaucoma drugs in Ireland 1996-2003. Br J Ophthalmol. 2006;90: 162-5.

6. Lee PP, Walt JG, Doyle JJ, et al. A multicenter, retrospective pilot study of resource use and costs associated with severity of disease in glaucoma. Arch Ophthalmol. 2006;124:12-9.

7. German EJ, Hurst MA, Wood D. Reliability of drop size from multidose eye drop bottles: is it cause for concern? Eye (Lond). 1999; 13 (Pt 1):93-100.

8. Narayanaswamy A, Neog A, Baskaran M, et al. A randomized, crossover, open label pilot study to evaluate the efficacy and safety of Xalatan in comparison with generic Latanoprost (Latoprost) in subjects with primary open angle glaucoma or ocular hypertension. Indian J Ophthalmol. 2007;55:127-31.

9. Weir RE, Zaidi FH, Charteris DG, Bunce C, Soltani M, Lovering AM. Variability in the content of Indian generic ciprofloxacin eye drops. Br J Ophthalmol. 2005;89:1094-6.

10. Canter LB. Ophthalmic generic drug approval process: implications for efficacy and safety. J Glaucoma. 1997;6:344-9.

11. Fiscella RG, Jensen M, Van Dyck G. Prednisolone suspension substitution. Arch Ophthalmol. 1998;116:703.

12. Garbe D. True extent of NSAID problems now becoming clearer. Ocul Surg News. 2000;2:43-4.

13. Fiscella RG, Gaynes BI, Jensen M. Equivalence of generic and brand name ophthalmic products. Am J Health Syst. 2001;58: 616-7. 